\title{
Phytochemical Constituent and Antioxidant Potential of Hyptis suaveolens (L.) Poit Leaf
}

\author{
Chigor, C. B. \\ Department of Biological Sciences, Faculty of Natural Sciences, Chukwuemeka Odumegwu Ojukwu University, Anambra State, Nigeria.
}

E-mail: chinyerechigor@yahoo.com

\begin{abstract}
The present study was carried out to evaluate the phytochemical constituents and antioxidant activity of the leaf extract of Hyptis suaveolens, a plant with wide application in Igbo people's traditional medicine and food. Preliminary and quantitative phytochemicals constituents of Hyptis suaveolens were evaluated using standard methods. Antioxidant potentials of the ethanol extract were evaluated spectrophotometrically against 1,1-diphenyl-2-picrylhydrazyl (DPPH), ferric reducing power and chelating properties The result of the preliminary phytochemical analysis showed the presence of saponin, tannin, flavonoid, alkaloid, cyanogenic glycoside, phenol and anthocyanin in water and ethanol extracts. The quantitative phytochemical evaluation revealed that the leaves of Hyptis suaveolens contain tannin in the highest concentration $(0.77 \pm 0.001 \%)$, followed by Phenol $(0.68 \pm 0.002 \%)$, Flavonoid $(0.57 \pm 0.02 \%)$, Saponin $(0.36 \pm 0.015 \%)$, anthocyanin $(0.15 \pm 0.01 \%)$ and steroid $(0.07 \pm 0.00 \%)$ as the least in phytochemical content of Hyptis suaveolens. The plant extract also demonstrates antioxidant activities in form of scavenging, chelating and reducing activities. The result of the analysis showed that this plant also have relatively high scavenging activity (54.80\%), reducing activity (38.54\%), and chelating activity of (32.14\%). Hyptis suaveolens is in no doubt a potential medicinal plant considering its phytochemical constituents and antioxidant activities which compares favourably with the standard BHT.
\end{abstract}

Original Research Article

Received: $29^{\text {th }}$ Dec., 2017

Accepted: $18^{\text {th }}$ Jan., 2018

Published: $14^{\text {th }}$ Mar., 2018

\section{Keywords:}

Phytochemical

Antioxidant

Free radicals

Hyptis sauveolens

\section{INTRODUCTION}

$\mathrm{F}$ Tree radicals reactive oxygen species and reactive nitrogen species are generated by our body by various endogenous systems or exposure to X-rays, ozone, cigarette smoking, air pollutants, and industrial chemicals (Lobo et al., 2010). If free radicals overwhelm the body's ability to regulate them, a condition known as oxidative stress ensues. Free radicals thus adversely alter lipids, proteins, and DNA and trigger a number of human diseases (Lobo et al., 2010). Human bodies are protected from oxidative damage of free radicals through some complex defence systems which are called antioxidants (Rajkapoor et al., 2010). Antioxidants work to maintain the oxidant at optimum level and reduce free radicals.

Several standard established antioxidant drugs and synthetic antioxidants such as butylhydroxytoluene (BHT) and Rutin, are in recent past reported to be dangerous to living cells. As a result, attention has shifted from synthetic to natural antioxidants (Ewa et al., 2009). Considering the increasing risk factors of human to various deadly diseases, there has been a rise, globally, toward the use of natural substance present in medicinal plants as therapeutic antioxidants (Lobo et al., 2010). Plants are endowed with substances or compounds such as vitamins, terpenoids, phenolic acids, tannins, flavonoids, alkaloids, and other metabolites, which are rich antioxidants and act as free radical or active oxygen scavengers (Ebrahimzadeh et al., 2010).

In addition, the ingestion of natural antioxidants has been reported to promote the state of well-being or health and reduce risks of cancer, cardiovascular disease, diabetes, and other diseases associated with ageing (Lobo et al., 2010). Natural antioxidants and their radical scavenging potential have been reported in several ethnomedicinal plants (Chanda and Baravalia, 2010; Vaghasiya and Chanda, 2007). 
Hyptis suaveolens also known as pignut or chan is a pseudocereal plant, belonging to the family Lamiaceae. It is distributed in tropical and sub-tropical regions of the world, the West Indies and South America. It is an erect annual herb, branched and measuring between $50 \mathrm{~cm}$ and $2 \mathrm{~m}$ in height. It is a plant strongly aromatic. Hyptis suaveolens serve as an analgesic and decongestant; also used to relieve fever and to fuel blood circulation (Sharma et al., 2013). H. suaveolens is traditionally used to heal wounds and treat gastrointestinal disorders, respiratory tract, uterus infections and skin diseases (Oliveira et al., 2005; Kumar and Abbas, 2012). A leaf poultice is applied to cancers and tumours, and their aqueous extract has showed an antinociceptive effect (Santos et al., 2007). This study was undertaken to evaluate the phytochemical constituents and antioxidant properties present in Hyptis suaveolens leaf, which are used for various medicinal purposes.

\section{MATERIALS AND METHODS}

\subsection{Collection and identification of plant materials}

The leaves of Hyptis suaveolens were used for this study. The leaves were collected in an uncultivated land around Chukwuemeka Odumegwu Ojukwu University, Uli and were identified and authenticated by Mr Ogbonnaya of Ceslab Laboratory Umudike, Abia State.

The fresh leaves of $H$. suaveolens were washed with clean water to remove dirt and sand, drained and chopped. They were dried under shade for several days and then ground.

\subsection{Preliminary phytochemical screening}

The phytochemical analysis of the leaves of $H$. suaveolens were carried out using the method as described by Harborne (2006) to identify the presence of the different phytochemicals in the leaves before quantitative analysis was carried out.

\subsection{Quantitative Phytochemical analysis}

\subsubsection{Determination of alkaloids.}

This was done by the alkaline precipitation gravimetric method described by Harborne (2006). Five grams of the powdered plant sample was dispersed into $50 \mathrm{ml}$ of $10 \%$ acetic acid solution in ethanol. This was shaken very well and allowed to stand for $4 \mathrm{hrs}$. It was later filtered via Whatman no. 42 grade of filter paper. The filtrate was concentrated to a quarter of its original volume using a water bath. Concentrated ammonium hydroxide was added drop wise into the extract until precipitation was complete. The alkaloid precipitate was recovered by filtration using a weighed filter paper and washed with $1 \%$ ammonia solution $\left(\mathrm{NH}_{4} \mathrm{OH}\right)$ dried in the oven at $80^{\circ} \mathrm{C}$ for an hour, it was cooled and reweighed., The weight of the alkaloid was determined by weight difference and expressed as a percentage of the sample analyzed.

\subsubsection{Determination of flavonoids}

This was determined gravimetrically by the methods of Haborne (2006). Exactly $5 \mathrm{ml}$ of the powdered sample was boiled in $100 \mathrm{ml}$ of $2 \mathrm{M} \mathrm{HCl}$ solution for 30 mins, the boiled mixture was allowed to cool and then filtered. Ethyl acetate was added dropwise into the filtrate in until in excess. The precipitation flavonoid was recovered by filtration using a weighed filter paper and dried in an oven at $80^{\circ} \mathrm{C}$, cooled and reweighed. The difference in weight gave the weight of flavonoid which was expressed as a percentage.

\subsubsection{Determination of tannins}

Tannin content was determined according to the Folin Dennis modified method used by Kirk and Sawyer (1991). Five grams of the sample was dispersed in $50 \mathrm{ml}$ of distilled water and allowed to stand for 30 mins, being shaken every 10 mins. The mixture was filtered and the filtrate was used for experiment.

Two millilitres of the supernatant was measured into a $50 \mathrm{ml}$ volumetric flask. Similarly tannic acid solution and $5 \mathrm{ml}$ of distilled water were measured into separate flasks to serve as standard and blank respectively. They were also diluted with $35 \mathrm{ml}$ of distilled water separately. $1 \mathrm{ml}$ of Folin-Dennis reagent was added to each of the flasks, followed by $2.5 \mathrm{ml}$ of saturated sodium carbonate solution $\left(\mathrm{Na}_{2} \mathrm{CO}_{3}\right)$. The content of each flask was topped up to $50 \mathrm{ml}$ mark with distilled water and incubated for 90 mins. The absorbance of the developed color was measured at $620 \mathrm{~nm}$ wavelength in a spectrophotometer readings were taken with the reagent blank zero. The experiment was carried out in triplicate.

\subsubsection{Determination of saponin}

Saponin content was estimated using the double solvent extraction gravimetric method (Haborne, 1998). Five grams of the powdered sample was weighed out and mixed with 50 $\mathrm{ml}$ of $20 \%$ aqueous ethanol solution. The mixture was heated with periodic agitation on a water bath for 90 mins at $55^{\circ} \mathrm{C}$. It was filtered and the residue re-extracted with $50 \mathrm{ml}$ of the $20 \%$ ethanol. Both extracts were combined together. The combined extracts were reduced to $40 \mathrm{ml}$ using a water bath at $90^{\circ} \mathrm{C}$. The concentrate was transferred into a $750 \mathrm{ml}$ separating funnel where $40 \mathrm{ml}$ of diethyl ether was added and shaken vigorously. The ether layer was discarded while the aqueous layer was recovered. Re-extraction by partition was done repeatedly until the aqueous layer became clear in color. The saponins were extracted with $60 \mathrm{ml}$ of normal butanol. The normal butanol extract were washed with $5 \%$ aqueous $\mathrm{NaCl}_{2}$ (sodium chloride) solution and evaporated to dryness in a pre-weighed evaporating disc. It was dried at $60^{\circ} \mathrm{C}$ in the oven and weighed. The experiment was repeated three times.

\subsubsection{Determination for steroids}

The steroid content was evaluated based on the procedure of Okeke and Elekwa (2003). Five grams of the plant sample was dispersed in $100 \mathrm{ml}$ freshly distilled water and shaken very well to obtain a homogenous mixture. The homogenate was filtered and the filtrate was eluted with normal ammonium hydroxide solution (PH 9). One $\mathrm{ml}$ of the eluate was put into a flask $(250 \mathrm{ml}) 2 \mathrm{ml}$ of chloroform was added to it. $3 \mathrm{ml}$ of ice cold acetic anhydride was added to the mixture in the flask and 3 drops of concentrated $\mathrm{H}_{2} \mathrm{SO} 4$ was gradually and carefully added to cool. Standard sterol 
solution was prepared and treated as described above to serve as standard and prepared sample was measured in a spectrophotometer at $420 \mathrm{~nm}$ wavelength, using the reagent as blank. The experiment was carried out in triplicates.

\subsubsection{Determination of anthocyanin}

This was done by the gravimetric method modified. Five grams of each test sample was hydrolysed by boiling in 100 $\mathrm{ml}$ of $2 \mathrm{ml} \mathrm{HCl}$ for 30 mins. The hydrolysate was filtered afterwards. The filtrate was transferred into a separation funnel where equal volume of ethyl acetate was added to it, and shaken vigorously. The aqueous layer was discarded, while the ethyl acetate layer (extract) was recovered. The extract was evaporated to dryness over a steam bath. The dried extract was then treated with concentrated amyl alcohol to extract the anthocyanin and filtered. After filtration, the extract was evaporated to dryness. It was then dried in an oven at $30^{\circ} \mathrm{C}$ for $20 \mathrm{mins}$ and cooled in a Desiccator. The weight of anthocyanin was determined and expressed as percentage of the weight analyzed.

\subsubsection{Determination of phenol}

Total phenolic contents were evaluated with FolinCiocalteu's phenol reagent (AOAC, 2000). Dried sample (0.2 g) was mixed in $10 \mathrm{ml}$ of methanol and shaken. The mixture was allowed to stand for 30 mins and then filtered. Exactly 1 $\mathrm{ml}$ of the extract solution was mixed with $1 \mathrm{ml}$ of Folin's reagent previously diluted with distilled water. The colour was allowed to develop for about 3 to $4 \mathrm{hrs}$ at room temperature. The absorbance of the developed colour was measured at $760 \mathrm{~nm}$ wavelength. The experiment was conducted in triplicate and the results were expressed as mean $\pm \mathrm{SD}$ values.

\subsection{Determination of antioxidant activities of Hyptis suaveolens}

\subsubsection{DPPH-Scavenging activities}

Scavenging activity was determined by spectrophotometry using the procedure described by Akter et al (2010). A measured quantity $0.1 \mathrm{ml}$ of the extract was mixed with 1.5 of 0.02m DPPH (2, 2 diphenyl-1-1 picryl hydrazyl) solution in a test tube. Similarly, $0.1 \mathrm{ml}$ of standard antioxidant, BHT (butylated hydrotoluene) was put in a separate test tube and mixed with $1.5 \mathrm{ml}$ of the DPPH solution. Both the sample and the standard were incubated in the dark at room temperature for 30 mins. The absorbance of both was read in a spectrophotometer at a wavelength of $517 \mathrm{~nm}$. A reagent blank was used to set the instrument at zero. The scavenging activity was calculated, relative to the standard antioxidant as thus:

$\%$ scavenging activity $=\mathrm{As}-\mathrm{Au}$

Where;

As $=$ Absorbance of the standard antioxidant at $517 \mathrm{~nm}$.

$\mathrm{Au}=$ Absorbance of the test sample at $517 \mathrm{~nm}$.

\subsubsection{Determination of antioxidant reducing power}

The reducing power was determined using the method of Rusak et al. (2008). Twenty grams of the sample was mixed in $200 \mathrm{ml}$ of distilled water. Then $200 \mathrm{ml}$ of ethanol was added to the aqueous mixture, shaken well for $15 \mathrm{~min}$ and the mixture was filtered through a moisten cloth. The extract (filtrate) was hydrolysed by boiling a measured volume of 20 $\mathrm{ml}$ in $80 \mathrm{ml}$ of $2 \mathrm{M} \mathrm{HCl}$ for $30 \mathrm{mins}$ in a water bath. The hydrolysate was put into a separate tube and $80 \mathrm{ml}$ of diethyl ether was added into it. The extraction was repeated. The extract was heated over a water bath to dry. The residue was dissolved in $20 \mathrm{ml}$ of $95 \%$ ethanol and put in a screw capped universal bottle and stored in a deep freezer until needed for analysis the next day to determine the FRAP. $0.2 \mathrm{ml}$ of the extract was mixed with $3.8 \mathrm{ml}$ of the FRAP reagent and allowed to stand for 4 mins. Meanwhile, a standard antioxidant solution BHT was prepared and diluted to a concentration of $750 \mathrm{~nm}$ of $\mathrm{Fe}^{2+}$. Also $0.2 \mathrm{ml}$ of the standard solution was also treated with FRAP reagent and stood for 4 mins as well. Absorbance of both the sample extract and the standard antioxidant were measured at $600 \mathrm{~nm}$ in a spectrophotometer. A reagent blank was used to set instrument at zero. The reducing power was calculated thus:

FRAP; Ferric reducing antioxidant power $=\mathrm{As}-\mathrm{Au}$

As $=$ Absorbance of the standard antioxidant

$\mathrm{Au}=$ Absorbance of the sample extract

\subsubsection{Chelating activity}

Chelating activity of Hyptis suaveolens was determined by their ability to chelate ferrous ions $\mathrm{Fe}_{2}+$ using the spectrophotometer method adapted by Ebrahimzadeh et al. (2009). A unit volume $1 \mathrm{ml}$ of the plant sample extract was mixed with $3.7 \mathrm{ml}$ of ferrozin and $0.1 \mathrm{ml}$ of $2 \mathrm{M}$ Ferrous chloride solution was added to it. To initiate the reaction, 0.2 $\mathrm{ml}$ of $5 \mathrm{~mm}$ ferozine was added. The mixture was kept in an ambient temperature to react for 10 mins. Meanwhile, standard chelating agent 0.02n EDTA solution was treated the same way as described above. The absorbance of the sample standard and ferrozin control (in which no sample extract was added) was read at $562 \mathrm{~nm}$ wavelength in a spectrophotometer.

\section{RESULTS}

The preliminary phytochemical investigation (Table 1) showed the presence of sponin, tannins, phenols, anthocyanin, alkaloids, flavonoids and steroids in ethanol extract of the leaf while only tannin and HCN were detected in the aqueous extract.

Table 1: Preliminary Phytochemical investigation.

\begin{tabular}{lll}
\hline Phytochemical constituents & $\begin{array}{l}\text { Water } \\
\text { extract }\end{array}$ & $\begin{array}{l}\text { Ethanol } \\
\text { extract }\end{array}$ \\
\hline Saponin & - & + \\
Tannin & + & + \\
Phenol & - & + \\
Anthocyanin & - & + \\
Alkaloid & - & + \\
HCN & + & - \\
Flavonoid & - & + \\
Steroid & - & + \\
\hline
\end{tabular}

Key: $(+)=$ Present, $(-)=$ Absent 
Table 2: shows the quantitative phytochemical analysis of Hyptis suaveolens. It could be seen that Hyptis suaveolens has tannin in the highest concentration $(0.77 \%)$,followed by phenol $(0.68 \%)$, flavonoids $(0.57 \%)$, alkaloid $(0.45 \%)$ which were moderate followed by anthocyanin $(0.15 \%)$, glycoside $(7.8 \%)$ and saponin $(0.36 \%)$. Steroids were slightly detected $(0.07 \%)$.

Table 2: Quantitative Phytochemical Analysis of Hyptis suaveolens

\begin{tabular}{ll}
\hline Phytochemicals & \% Constituent \\
\hline Saponin & $0.38 \pm 0.01$ \\
Tannin & $0.77 \pm 0.01$ \\
Flavonoid & $0.57 \pm 0.02$ \\
Alkaloid & $0.45 \pm 0.01$ \\
Phenol & $0.68 \pm 0.02$ \\
Steroid & $0.07 \pm 0.00$ \\
Anthocyanin & $0.15 \pm 0.01$ \\
HCN & $7.80 \pm 8.84$ \\
\hline (Values are means of 3 replicates \pm SD- standard deviation)
\end{tabular}

The antioxidant activities of the leaf of $H$. sauveolens are presented in Table 3. The result shows reducing activity of $38.54 \pm 0.26 \%$ as against the standard BHT of $44.8 \%$, chelating activity of $32.14 \pm 0.13 \%$ compared to standard BHT of $36.6 \%$ and scavenging activity of $54.80 \pm 0.42 \%$ compared to standard BHT (52.4\%). The scavenging activity is highest of all the antioxidant activities while the chelating activity is the least.

Table 3: Antioxidant activities of Hyptis sauveolens

\begin{tabular}{lll}
\hline Antioxidant Properties & $\begin{array}{l}\text { Plant } \\
\text { extract }\end{array}$ & $\begin{array}{l}\text { Standard } \\
\text { (BHT) }\end{array}$ \\
\hline Reducing Activity (\%) & $38.54 \pm 0.26$ & 44.8 \\
Chelating Activity (\%) & $32.14 \pm 0.13$ & 36.6 \\
Scavenging Activity (\%) & $54.80 \pm 0.42$ & 52.4 \\
\hline
\end{tabular}

(Values are means of 3 replicates \pm SD- standard deviation).

\section{DISCUSSION}

The detection of more phytochemical compounds in ethanol extract of the leaf than in aqueous extract in preliminary screening is an indication that ethanol is a better solvent than water for the extraction of phytochemicals in Hyptis suaveolens. The result of qualitative analysis of $H$. suaveolens showed the presence of alkaloid, saponin, flavonoid, and tannin in the ethanolic extract which is similar to the findings of Shaikat et al. (2012). However, the presence of steroid and phenol recorded in this study is in contrast to what has been reported by the researchers (Shaikat et al., 2012).

Tannin content was the highest of all the phytochemicals evaluated in this study. Okwu (2004) reported that tannins are organic substances of diverse composition with pronounced astringent properties which precipitates protein and hasten the healing of wound and inflamed mucor membrane. They have been implicated with various pharmaco-therapeutic effects (Ferreira et al., 2008). Tannins-rich remedies are used as antihelmintics, antimicrobials, antioxidants and antivirals (Buzzini et al., 2008; Koleckar et al., 2008). The presence of tannins in the ethanol extract of $H$. suaveolens leaves observed in the present study demonstrates the possible efficacy of therapeutic use of $H$. suaveolens. Tannin and phenols are the major plant secondary metabolites responsible for the antioxidant activities. This activity is proposed to be due to a chain- breaking mechanism by which the primary antioxidant donates an electron to the free radical present in the systems or by removal of ROS/reactive nitrogen species initiators (Lobo et al., 2010).

The phenol content $(0.68 \%)$ was the second largest phytochemical detected. Phenol is considered to be potentially toxic to the growth and development of pathogens. It has been associated with astringency, discolouration and inhibition of some enzyme activity (Okwu, 2004). Phenolics show an array of health promoting benefits in human health such as protecting the human body against bacterial and viral attacks thereby boosting the immune system. They are active in curing kidney and stomach problems and are also anti-inflammatory in action (Maobe et al., 2012).

Flavonoids are phenolic acids which serve as an important antioxidant in different medicinal plants and related phytomedicines. Flavonoids are potent water-soluble, super anti-oxidant and free radical scavengers which prevent oxidative cell damage. (Okigbo et al., 2009). The Flavonoids have antioxidant powers that may provide important health benefits. Flavonoids have various effects including antiinflammatory, anti-carcinogenic, hepatoprotective, antithrombotic and anti-viral properties (Tapas et al., 2008). The presence of flavonoids and other compounds such as saponins, alkaloids and tannins in Hyptis suaveolens could suggest their traditional use for the treatment of various illnesses.

Hyptis suaveolens also contain alkaloids which are widely used in medicine due to their toxicity. Mensa et al. (2008) observed that alkaloids are currently recognized more for their pharmacological activities than for their toxicity. This result shows that the leaves have potential to protect consumers from oxidative cell malfunction.

The demonstrated antioxidant activity was attributed to its rich phytochemicals, many of which have anti-oxidative components. Tannin, phenolics, flavonoid, alkaloids etc. are components of phytochemicals which have been established to possess strong antioxidant activity.

The reducing power of the plant extract was determined by measuring the transformation of $\mathrm{Fe}^{3+/}$ ferricyanide complex to $\mathrm{Fe}^{2+}$ ferrous form (Park and Jhon, 2010). The reducing properties of the plant extracts are generally associated with the presence of reductones, which have been shown to exert antioxidant action by breaking the free radical chain and donating a hydrogen atom (Rajkapoor et al., 2010). DPPH being a stable free radical accepts electrons or hydrogen radicals to become a stable diamagnetic molecule. Antioxidants on interaction with DPPH, transfer electrons or hydrogen atoms to DPPH and thus neutralize its free radical character converting to 1-1diphenyl-2-picryl hydrazine as represented by the degree of discoloration (Thambiraj et al., 2012). Hence, DPPH is usually used as a substance to evaluate the antioxidant activity. The leaf extract of $H$. 
suaveolens scavenged DPPH better than the standard antioxidant.

The demonstrated antioxidant activity coupled with high concentration of phytochemicals in the Hyptis suaveolens leaves show the potential health benefits derivable from use of the leaves in medicine.

\section{CONCLUSION}

Leaf extract of Hyptis suaveolens possess antioxidant properties comparable to the standard antioxidants and could serve as free radical inhibitors. The plant extracts have proven to possess pharmacological action due to the presence of various phytochemicals.

\section{REFERENCES}

Akter, S., Ahmed, M. and Eun, J.B. (2010). Solvent effects on antioxidant properties of persimmon (Diospyros kaki L. cv. Daebong) seeds. International Journal of Food Science and Technology, 45, 2258-2264.

AOAC (2000). Official method of analysis of the association of official / analytical chemist $17^{\text {th }}$ edition AOAC International.

Asekun, O.T., Ekundayo, O. \& Adeniyi, B.A. (1999). Antimicrobial activity of the essential oil of Hyptis suaveolens leaves. Fitoterapia, $70,440-442$.

Buzzini, P., Arapitsas, P., Goretti, M., Branda, E., Turchetti, B., Pinelli, P., Ieri, F. \& Romani, A. (2008). Antimicrobial and antiviral activity of hydrolysable tannins. Mini- Reviews in Medicinal Chemistry, 8, 1179-1187.

Chanda, S. \& Baravalia, Y. (2010). Screening of some plant extracts against some skin diseases caused by oxidative stress and microorganisms. African Journal of Biotechnology, 9, 3210-3217.

Ebrahimzadeh, M.A., Ehsanifar, S. \& Eslami, B. (2009). Sambucus ebulus elburensis fruits: A good source for antioxidants. Pharmacognosy Magazine, 4, 213-218.

Ebrahimzadeh, M.A., Nabavi, S.M., Nabavi, S.F., Bahramian, F. \& Bekhradnia, A.R. (2010). Antioxidant and free radical scavenging activity of $H$. officinalis, L. Var. angustifolius, V. odorata, B. hyrcana and C. speciosum. Pakistan Journal of Pharmaceutical Science, 23, 29-34.

Ewa, F., Ewa, I. \& Wojciech, P. (2009). Effect of pregnancy and tobacco smoke on the antioxidant activity of rutin in an animal model. Pharmacological Report, 61, 935-940.

Ferreira, D., Gross, G.G., Hagerman, A.E., Kolodziej, H. \& Yoshida, T. (2008). Tannins and related polyphenols: Perspectives on their chemistry, biology, ecological effects, and human health protection. Phytochemistry, 69, 3006-3008.

Harbone, J.B. (2006). Text book of phytochemical methods, $A$ Guide to Modern Techniques of Plant Analysis, $2^{\text {nd }}$ ed. Chapman and Hall Ltd. London. 207-221.

Kirk, R.S. \& Sawyer, R. (1991). Pearson's compositon and analysis of foods. London,UK. Ninth edition, Longman scientific Technical. pp:708.
Koleckar, V., Kubikova, K., Rehakova, Z., Kuca, K., Jun, D., Jahodar, L. \& Opletal, L. (2008). Condensed and hydrolysable tannins as antioxidants influencing the health. Mini- Reviews in Medicinal Chemistry, 8, 43.

Lobo, V., Patil, A., Phatak, A. \& Chandra, N. (2010). Free radicals, antioxidants and functional foods: Impact on human health. Pharmacognosy Review, 4(8), 118-126.

Maobe, M.A.G., Gitu, L., Gatebe, E. \& Rotich, H. (2012). Phytochemical Analysis of Phenol and Flavonoid in Eight Selected Medicinal Herbs Used for the Treatment of Diabetes, Malaria and Pneumonia in Kisii, Kenya. Academic Journal of Cancer Research, $5(2), 31-39$

Mensah, J.K., Okoli, R.I., Ohajuobodo, J.O. \& Efediyi. (2008). Phytochemical, nutritional and medical properties of some leafy vegetables consumed by Edo people of Nigeria. African Journal Biotechnology, 7, 2304-2309.

Okeke, C.U. \& Elekwa, I. (2003). Phytochemical study of the extract of Pterocarpus santalinoides. Journal of Health and visual sciences, 5(1), 47-55.

Okigbo, R.N., Anuagasi, C.I. \& Amadi, J.E. (2009). Advances in selected medicinal and aromatic plants indigenous to Africa. Journal of Medicinal Plants Research, 3(2), 86-95.

Okwu, D.E. (2004). Phytochemicals and vitamin content of indigenous spices of south Eastern Nigeria. Journal of sustainable Agricultural Environment, 6, 30-34.

Oliveira, M..J., Campos, I.F.P., Oliveira, C.B.A., Santos, M.R., Souza, P.S., Santos, S.C., Seraphin, J.C. \& Ferri, P.H. (2005). Influence of growth phase on the essential oil composition of Hyptis suaveolens. Biochemical Systematics and Ecology, 33, 275-285.

Park, E.J. \& Jhon, D.Y. (2010). The antioxidant, angiotensin converting enzyme inhibition activity, and phenolic compounds of bamboo shoot extracts. LWT-Food Science and Technology, 43, 655-659.

Rajkapoor, B., Burkan, Z.E. \& Senthilkumar, R. (2010). Oxidants and human diseases: role of antioxidant medicinal plants-a review. Pharmacology Online, 1, 11.

Santos, T.C., Marques, M.S., Menezes, I.A.C., Dias, K.S., Silva, A.B.L., Mello I.C.M., Carvalho, A.C.S., Cavalcanti, S.C.H., Antoniolli, A.R. \& Marçal, R.M. (2007). Antinociceptive effect and acute toxicity of the Hyptis suaveolens leaves aqueous extract on mice. Fitoterapia, 78, 333-336.

Shaikat, M.Z.H, Hossain, M.T. \& Azam, M.G. (2012). Phytochemical Screening and Antidiarrhoeal Activity of Hyptis suaveolens. International Journal of Applied Research in Natural Products, 5(2), 1-4.

Sharma, P. P., Roy, R.K., Anurag, G. D. \& Sharma, V.K. (2013) Hyptis suaveolens (L.) poit: A phyto-pharmacological review. International Journal of Chemical and Pharmaceutical Sciences, $4(1)$

Singh, J., Upadhyay, A.K., Bahadur, A., Singh, B., Singh, K.P. \& Rai, M. (2006). Antioxidant phytochemicals in cabbage (Brassica oleracea L. var. capitata). Scientia Horticulturae, 108(3), 233-237. 
Tapas, A.R., Sakarkar, D.M. \& Kakde, R.B. (2008). Flavonoids as Nutraceuticals: A Review. Tropical Journal of Pharmaceutical Research, 7(3), 1089-1099.

Thambiraj, J. \& Paulsamy, S. (2012). In vitro antioxidant potential of methanol extract of the medicinal plant, Acacia caesia (L.) Willd". Asian Pacific Journal of Tropical Biomedicine, 2, 732-736.
Trease, G.E. \& Evans, W.C. (2002). Pharmacognosy. 15th Ed. Saunder Publishers, London pp. 42-44, 221-229, 246-249, 404-306, 331-332, 391-393.

Vaghasiya, Y. \& Chanda, S. (2007). Screening of methanol, acetone extracts of fourteen Indian medicinal plants for antimicrobial activity. Turkish Journal of Biology, 31, 243-248.

\section{$\underline{\text { How to cite this article }}$}

Chigor, C.B. (2018). Phytochemical Constituent and Antioxidant Potential of Hyptis suaveolens (L.) Poit Leaf, 2(2): 55-60. Doi: https://doi.org/10.25240/TJANS.2018.2.2.07.

Licensed under a Creative Commons Attribution 4.0 International License 